\title{
Bookshelf tour: categorização do conhecimento a partir do discurso coletivo dos booktubers
}

\author{
Admeire da Silva Santos Sundström \\ Doutoranda; Universidade Estadual Paulista, Marília, SP, Brasil; \\ admeire@gmail.com \\ João Batista Ernesto de Moraes \\ Doutor; Universidade Estadual Paulista, Marília, SP, Brasil; \\ jota@marilia.unesp.br
}

\begin{abstract}
Resumo: Existem diversas formas de se organizar o conhecimento e isso torna viável e necessário o estudo de instâncias populares de organização do conhecimento. Nesta pesquisa, o objeto de estudo é a comunidade booktube, que é composta por pessoas que dividem suas experiências literárias através de vídeos disponibilizados na plataforma YouTube. As análises dos vídeos permitiram classificar determinados booktubers como colecionadores de livros. Entende-se que o colecionismo bibliográfico ocorre em instância particular, é motivado por razões subjetivas e a organização desses acervos segue ordens próprias de cada colecionador, sendo assim, questiona-se: é possível aplicar a concepção de folksonomia para identificar as categorias de organização do conhecimento da comunidade booktube? O método é composto por duas etapas: a primeira, consiste na construção do aporte teórico, que buscou a definição conceitual dos assuntos relevantes para análise e interpretação dos dados. A partir disso, parte-se para a segunda etapa, que consiste no uso do Discurso do Sujeito Coletivo para extração dos termos utilizados pela comunidade em questão. Como resultado, percebeu-se a presença de categorias de organizações, a possibilidade do uso do Discurso do Sujeito Coletivo para categorização da linguagem natural e a memória coletiva implícita nesse sistema. Por fim, percebe-se a possibilidade de se utilizar a concepção de folksonomia para identificar modos de organização no colecionismo, os prós e os contras da linguagem natural em uma estrutura conceitual e a possibilidade de se interpretar a folksonomia em outros ambientes além da atual abordagem de processo ou produto de tagueamento na web 2.0.
\end{abstract}

Palavras-chave: Booktubers. Colecionismo bibliográfico. Memória coletiva. Folksonomia. Organização do conhecimento. 


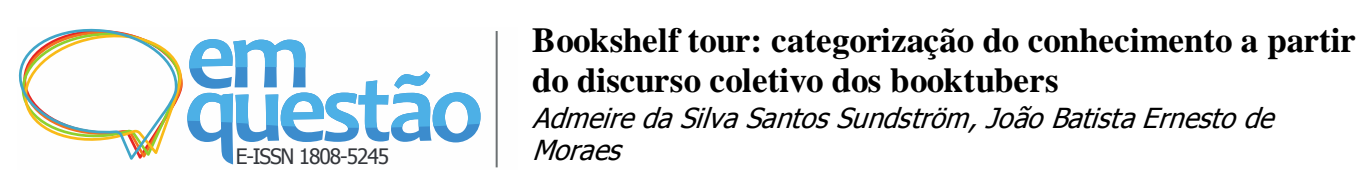

\section{INTRODUÇÃO}

A folksonomia, na Ciência da Informação, vem sendo tratada de dois modos bem pontuais: como um produto do ato de categorizar informação na web; e como um processo, o ato de categorizar, propriamente dito, por meio do uso de linguagem natural. Em ambas as concepções, o "insumo" é o ponto de vista do usuário. Com isso em vista, é que se buscou trazer essa concepção de folksonomia para entender o modo como os colecionadores tratam suas respectivas coleções.

Mas antes, cabe pontuar que o pressuposto empírico deste estudo salienta que a memória está subentendida durante o processo de tratamento das coleções particulares. Essa hipótese buscou seu respaldo na leitura de Benjamin (1987), em torno dos seus diálogos a respeito de coleções bibliográficas. Desse modo, os lugares de memória, como uma coleção de livros pode ser interpretada, estão para se referir à materialização do percurso sociocultural humano, e, também, representar, por meio da materialidade, a ideia de que algo físico pode rememorar o vivido (NORA, 1993).

Quando se fala em coleção particular, há uma referência aos livros formados por meio do colecionismo bibliográfico, sendo este compreendido como uma necessidade e/ou desejo por possuir livros; desejo visceral por coletar materiais bibliográficos; e, até mesmo, o preenchimento de um desejo subjetivo por meio de livros (MURGUIA, 2009).

As mídias digitais permitem que os colecionadores compartilhem suas experiências com livros e literatura na plataforma YouTube, o que caracteriza um novo perfil de colecionador. A nomenclatura utilizada para definir esse grupo é booktuber, palavra em inglês utilizada para se referir a uma pessoa apaixonada por livros e literatura que compartilha sua experiência no YouTube.

À luz dessa ambientação descrita acima, convém revistar a quinta premissa de Barité (2001), a respeito da importância de se abordar as diversas formas de se organizar o conhecimento. E, desse modo, para dialogar com o modo informal de organizar o conhecimento no colecionismo, cabe considerar a concepção de folksonomia. 


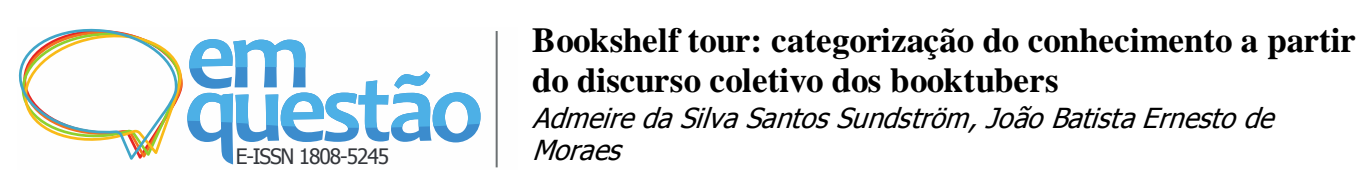

Assim, com tais elementos em vista e sob o prisma de que existem diversas formas de organizar o conhecimento, questiona-se: É possível aplicar a concepção de folksonomia para identificar as categorias de organização do conhecimento da comunidade booktube por meio da identificação dos termos utilizados por essa comunidade? E como essas instâncias populares de organizações podem contribuir para pesquisa em torno da Organização e Representação do Conhecimento (ORC)?

Logo, objetivou-se identificar, a princípio, as categorias de organização utilizados pelos booktubers, que disponibilizam vídeos no YouTube relatando seus modos de organização, mais especificamente na TAG BookShelf Tour (passeio pela estante). Diante disso, situando-se teórico-metodologicamente no Discurso do Sujeito Coletivo, recorrendo aos estudos de Fernando Lefevre, Ana Lefevre (2014) e também destes autores com Marques (2009), analisou-se o discurso de cinco booktubers, com o objetivo de transpor termos e estabelecer categorias de organizações, partindo do pressuposto de que a memória está implícita nesse processo e de que o colecionismo pode ser abordado na perspectiva da folksonomia.

Assim, a estrutura do artigo se divide da seguinte forma: primeiro, contém o aporte teórico que traz um panorama a respeito de Organização e Representação do Conhecimento, que abrange origem histórica, nomenclatura e concepção atual. Segue, trazendo as abordagens existentes sobre folksonomia. Após, traz a definição de colecionismo bibliográfico, mas centra nas questões relacionadas ao tratamento dado pelos colecionadores às suas respectivas coleções.

Em seguida, aborda a importância de se compreender a memória como instância presente no tratamento de coleções particulares. Apresenta a definição da comunidade booktube, origens da nomenclatura e estudos já realizados em torno dessa comunidade. Detalha a metodologia escolhida, bem como são feitos a tabulação e análise dos dados. E finaliza apresentando um esquema de categorização gerado por meio do mapeamento de termos identificados nos discursos dos booktubers. 


\section{ORGANIZAÇÃO E REPRESENTAÇÃO DO CONHECIMENTO}

Historicamente, o ato de organizar o conhecimento remete à Antiguidade e, por meio da Filosofia, Aristóteles fundou as bases lógicas e epistemológicas que ainda norteiam o pensamento atual do Ocidente. Assim, por muito tempo, a sistematização do conhecimento humano foi atividade destinada a monges e, em seguida, a cientistas (BARITÉ, 2001, p. 38).

Desse modo, campos diversos do saber sentiam a necessidade de se sistematizar o conhecimento, mas foi depois do século XIX, com a concepção de biblioteca pública e expansão da economia e revolução industrial que se notou a necessidade de instrumentos que viabilizasem a "[...] recuperação do documento de um modo estruturado.” (BARITÉ, 2001, p. 39, tradução nossa).

Barité (2001) afirma que, com base na Ciência e na Filosofia, os instrumentos começam a ser criados. Mas é Ranganathan, precursor dos sistemas de classificação especializados e tesauros, quem apresenta um avanço significativo para área, pautada na necessidade social da informação, a Organização do conhecimento visa a "[...] fornecer os conceitos e instrumentos adequados para o tratamento do conhecimento socializado." (BARITÉ, 2001, p. 39-40, tradução nossa).

A nomenclatura Organização do Conhecimento teve origem no livro Organization of Knowledge in Libraries, de Henry Bliss, em 1933. Mas só em 1971 é que a expressão KO foi adotada pelos pesquisadores da área (BARITÉ, 2001, p. 40). No entanto, as discussões em torno de dado, informação e conhecimento são sempre recolocadas como pauta de análise para a Ciência da Informação. E, de acordo com Barité (2001), dado é “[...] toda unidade autônoma de saber." Informação é "todo conjunto organizado de dados.” E conhecimento é "“...] um saber humano socializado [...] um processo intelectual em que o indivíduo compreende e incorpora os fenômenos do mundo exterior para si, estando, desse modo, em constante revisitação. " (BARITÉ, 2001, p. 4344, tradução nossa).

Portanto, a interação com o social do conhecimento ocorre por meio dos documentos. Sendo assim, a Organização do Conhecimento estuda, analisa e 
elabora ferramentas e instrumentos que tornam prática e efetiva essa socialização. Na instituição, esse conhecimento deve ser estruturado e representado por meio de códigos pré-determinados, de modo que o usuário possa recuperá-lo.

Um sistema de recuperação de informação prevê duas abordagens fundamentais: a análise chamada "física" ou "descritiva" do documento, que consiste na descrição de dados bibliográficos como: autoria, editora, número de páginas, ano de publicação, etc.; e a análise de "conteúdo" ou "temática" do documento, em que o conteúdo do documento é representado por meio de conceitos, termos. "A representação física de um documento pode ser comum em diferentes sistemas, mas a representação temática pode variar." (KOBASHI; FRANCELIN, 2011, p. 11)

Kobashi e Francelin (2011) ainda ressaltam que "Nos processos de tratamento e recuperação da informação, o conceito, tanto na etapa de análise do documento, quanto na tradução com fins de padronização, ocupa lugar central. " (KOBASHI; FRANCELIN, 2011, p. 11).

O conhecimento é organizado por meio do sistema de conceitos (BARITÉ, 2001). Desse modo, devido à particularidade da linguagem no colecionismo bibliográfico, é que se busca identificar, nesse primeiro momento, as categorias de organização, para, então, propor o mapeamento dos conceitos que compõem o processo de tratamento e recuperação da informação.

Ressalta-se, nesse primeiro momento, que o objeto de análise desta pesquisa não utiliza a linguagem documental para o tratamento da informação; deste modo, no contexto da Ciência da Informação, existem estudos na área da folksonomia que trabalham a questão da classificação em âmbito social e abordam a importância da linguagem natural em sistemas de organização do conhecimento, e é nesta perspectiva que se traz essa abordagem para o presente artigo. 


\subsection{Folksonomia}

Tendo em vista a concepção da web 2.0, surgiram comportamentos cada vez mais interativos no ciberespaço e, com isso, a necessidade de se pensar a participação direta dos usuários nos processos relacionados ao tratamento da informação, em especial, às formas de organização, compartilhamento e recuperação da informação.

Desse modo, Wal (2004) cunha o conceito de folksonomia, e Moura (2009), ao fazer uma retomada desse conceito, traz a etimologia da palavra. A autora afirma que folksonomia se trata de um neologismo resultante da união de duas outras: folk (povo, em inglês) e taxonomia (classificação). Assim, o sentido mais próximo para o conceito é: classificação das pessoas ou classificação popular.

Moura (2009) salienta que o termo é usado por muitos autores como sinônimo de: "[...] ethnoclassification, collaborative tagging, social bookmarking, social tagging, narrow folksonomy, taxonomia popular, classificação social, dentre outros”. (MOURA, 2009, p. 63).

Ao recuperar a leitura de Wal (2004), cabe destacar a seguinte definição:

A folksonomia é o resultado da marcação livre e pessoal de informações e objetos (qualquer coisa com uma URL) para a própria recuperação. A marcação é feita em um ambiente social (geralmente compartilhado e aberto a outras pessoas). A folksonomia é criada pela pessoa consumidora de informações a partir do ato de marcar (WAL, 2004, doc não paginado, tradução nossa).

O estudo de Wal (2004) é constantemente revisitado por autores brasileiros que estudam o assunto e, desse modo, Catarino e Baptista (2007), ao revisarem os estudos na área da Ciência da Informação a respeito dos enfoques dados à folksonomia, destacam dois modos distintos de abordar o conceito, que correspondem aos modos de interpretar a definição do autor: "[...] como o resultado de um processo, como um produto, concordando desta forma com o conceito de Wal e [...] como sendo um sistema, uma metodologia, ou abordagem, ou o próprio processo." (CATARINO; BAPTISTA, 2007, p. 4). 
Desse modo, a folksonomia pode ser interpretada como o ato de marcar, com o uso da linguagem natural, em instância independente, elementos dispostos na internet, cuja elaboração é feita por usuários de um determinado sistema e recebe o nome de etiquetagem ou marcação (tagging), o que a caracteriza como o processo, uma abordagem e/ou uma metodologia.

A folksonomia também pode ser interpretada como os termos resultantes dessa marcação; o conjunto de palavras que caracterizam determinado elemento no ambiente digital. Assim, a folksonomia é também entendida como o resultado do processo, isto é, um produto (CATARINO; BAPTISTA, 2007).

O que ambas as abordagens concordam é que: a folksonomia ocorre em um ambiente aberto, está relacionada à presença de termos (seja como processo ou como produto) e o insumo é o olhar do usuário, que utiliza seu próprio vocabulário, linguagem natural, como pistas para que determinado objeto seja organizado e recuperado.

Essa marcação trata-se de uma indexação informal na web, pois é caracterizada pelo uso da linguagem natural, sem políticas ou controle de vocabulário e sem o monitoramento de um profissional da informação. Outros usuários também podem recuperar a informação por meio desses termos, bem como contribuir nesse processo de etiquetagem, mesmo quando este já foi iniciado por outros usuários (CATARINO; BAPTISTA, 2007).

\footnotetext{
Destacam-se, portanto, três fatores essenciais: (1) é resultado de uma indexação livre do próprio usuário do recurso; (2) objetiva a recuperação a posteriori da informação e (3) é desenvolvida num ambiente aberto que possibilita o compartilhamento e, até, em alguns casos, a sua construção conjunta. (CATARINO; BAPTISTA, 2007, p. 3).
}

Os estudos em torno da folksonomia apresentam pontos fortes e fracos dessa etiquetagem. O olhar positivo argumenta em torno da exaustividade no momento de descrição, o que remete a uma maior recuperação da informação e à participação do usuário durante o processo de organização. Em contrapartida, a presença da linguagem natural traz os problemas em torno dos sinônimos, ausência do controle do vocabulário e repetição de termos. 
Abaixo segue o quadro construído com base no texto de Barros (2011), no qual a autora apresenta a diferença entre as características da folksonomia, enquanto um processo, em comparação com os processos tradicionais de tratamento da informação.

Quadro 1 - Quadro comparativo entre folksonomia e sistemas tradicionais

\begin{tabular}{|l|l|}
\hline Característica da folksonomia & Sistemas tradicionais \\
\hline O usuário organiza a informação & Os profissionais organizam a informação \\
\hline Ousuário utiliza o próprio vocabulário & $\begin{array}{l}\text { Utiliza linguagem documental e/ou } \\
\text { linguagem natural }\end{array}$ \\
\hline $\begin{array}{l}\text { Usuário compartilha a percepção de } \\
\text { classificação com outros usuários }\end{array}$ & $\begin{array}{l}\text { O profissional classifica sem a participação } \\
\text { do usuário }\end{array}$ \\
\hline $\begin{array}{l}\text { A classificação pode ser feita e alterada em } \\
\text { qualquer momento }\end{array}$ & $\begin{array}{l}\text { A classificação é alterada somente por } \\
\text { profissionais e demanda tempo }\end{array}$ \\
\hline $\begin{array}{l}\text { A classificação não é submetida a outros } \\
\text { usuários ou profissionais }\end{array}$ & $\begin{array}{l}\text { A classificação é submetida às políticas de } \\
\text { indexação da instituição a qual pertença }\end{array}$ \\
\hline $\begin{array}{l}\text { Feed back imediato - troca de etiquetas } \\
\text { menos utilizadas por outras mais utilizadas }\end{array}$ & $\begin{array}{l}\text { Pode ocorrer demora em avaliar a adequação } \\
\text { dos termos }\end{array}$ \\
\hline $\begin{array}{l}\text { Os usuários negociam significados com outros } \\
\text { usuários }\end{array}$ & $\begin{array}{l}\text { Nem sempre há troca entre profissionais e } \\
\text { usuários }\end{array}$ \\
\hline
\end{tabular}
Fonte: Adaptado de Barros (2011, p. 20-21).

Assim, essa concepção de participação direta dos usuários no processo de organização e recuperação da informação, nomeada de folksonomia, será buscada com vista a interpretar e elucidar esse processo de organização e recuperação da informação no colecionismo bibliográfico compartilhado em ambiente digital, no caso, na plataforma YouTube.

\subsection{Colecionismo bibliográfico}

Reunir objetos, que fazem parte das relações sociais e culturais, é um comportamento que remonta desde os primórdios e é configurado de acordo com as características sociais (SANTOS, 2015).

O colecionismo é um ato em que o indivíduo seleciona, elege e organiza objetos à luz das necessidades particulares. Essas necessidades, por vez, são interpretadas como "[...] preenchimento de lacunas psicossociais; extensão de si, preservação do senso de continuidade histórica como vício ou investimento financeiro.”(FORMANEK, 2005, p. 327, tradução nossa). 


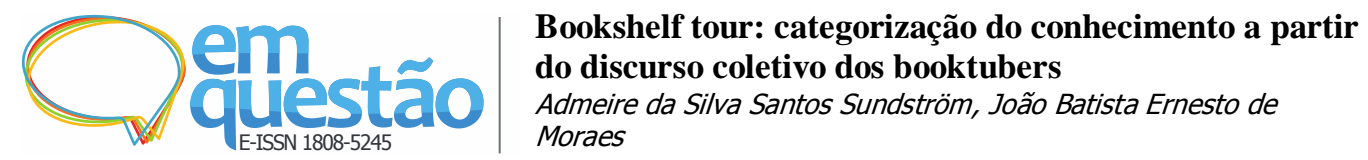

Como observado, o universo do colecionador é repleto de muita subjetividade, e, desse modo, a comunicação se volta para o colecionismo bibliográfico, em particular, os depoimentos de colecionadores em torno do processo de organização e recuperação da informação. Para entender um pouco esse universo, cabe revistar a leitura de Benjamin (1987) e Bartlett (2013).

Benjamin (1987) faz um convite à desordem dos livros, ao retirá-los da caixa, o autor afirma que "[...] o suave tédio da ordem ainda não os envolveu." (BENJAMIN, 1987, p. 227). E, ao desencaixota-los, começa a devanear sobre as relações que os livros têm com o seu colecionador e o modo como os livros são dispostos.

Contudo, direi mais ainda: o acaso e o destino que tingem o passado diante de meus olhos se evidenciam simultaneamente na desordem habitual desses livros. Pois o que é a posse senão a desordem na qual o hábito se acomodou de tal modo que ela só pode aparecer como se fosse ordem? (BENJAMIN, 1987, p. 228).

Para Benjamin (1987), os livros trazem o passado à tona na desordem em que se encontram, pois possuir um livro representa essa desordem que ordena as lembranças do colecionador. Desse modo, a desordem se torna uma ordem devido à representatividade dessa coleção. Assim, o autor complementa:

\footnotetext{
Nesse domínio, toda ordem é precisamente uma situação oscilante à beira do precipício. O único conhecimento exato - disse Anatole France - e o da publicação e do formato dos livros". Na prática, se há uma contrapartida da desordem de uma biblioteca, seria a ordenação de seu catálogo. (BENJAMIN, 1987, p. 228).
}

Percebe-se que, para um colecionador, não são todas as informações referentes ao livro que valem durante o processo de organização, pois, quando ele menciona os catálogos da biblioteca, fica subentendido que exista uma divergência entre a organização dos colecionadores e a organização institucional.

Outra passagem que subentende essa divergência é quando Benjamin (1987) afirma que acredita nos elementos envoltos aos livros para a elaboração de sua ordenação, ele ressalta os seguintes aspectos: “[...] imagens, lembranças 


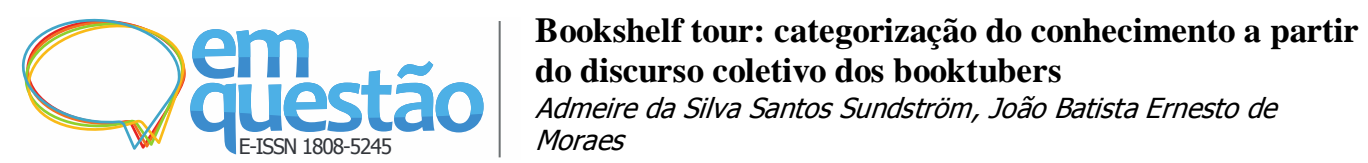

dos lugares onde os livros fizeram parte e de onde foram adquiridos." (1987, p. 229).

Bartlett (2013) apresenta a vida do colecionador John Gilkey, nome fictício utilizado para representar a história real de um homem capaz de fazer qualquer coisa para adquirir o livro desejado, até mesmo furtar.

No livro, são apresentados vários relatos em torno do processo de aquisição de obras raras do colecionador em questão, mas o ponto que merece destaque é a respeito da biblioteca de Thomas Jefferson, que, de acordo com os relatos do livro, possuía uma disposição doméstica e era ordenada, fisicamente, pela lógica do tamanho. Mas, após a mudança, Jefferson propôs um “[...] esquema de classificação que adotara de o progresso de aprendizado (The advancement of learning), de Francis Bacon, no qual os livros são organizados dentro de categoriais abrangentes, tais como memória, razão e imaginação [...]" (BARTLETT, 2013, p. 107).

Ao discorrer sobre sua opinião a respeito dessa classificação, Gilkey, o personagem central da trama, argumenta que, enquanto colecionador, prefere esse método, pois se interessa pela surpresa que essas relações apresentam. Ele ressalta que o método atrasa a recuperação da informação desejada se comparado aos métodos da biblioteconomia, no entanto, o colecionador não vê isso como um problema. Ele pontua que essa medida permite um conhecimento diferenciado da coleção, pois abre a possibilidade para a contemplação de outras obras.

Ambos os autores entendem que a disposição da coleção interfere no que ela representa. No entanto, o que foi percebido nessas leituras é que a disposição das obras tem um ponto de partida em comum para a categorização, que é a vida do colecionador.

O depoimento de Benjamnin (1987), a respeito de sua relação com os livros, subentende a presença da memória no processo de recuperação da informação desejada, pois o ato do colecionador de desencaixotar as obras traz as reminiscências de eventos que ocorreram em torno das obras. Desse modo, cabe elucubrar a respeito do conceito de memória identificado na fala do autor e que será adotado neste artigo. 


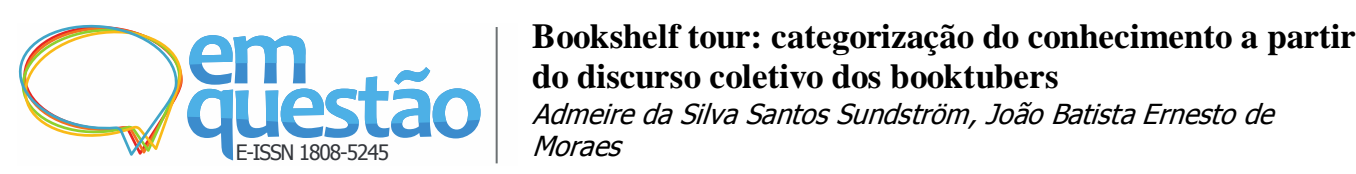

\subsection{Memória}

A memória é um fenômeno do presente, pois suas atualizações e o momento que ela ocorre são no presente. O seu aparecimento se dá devido a uma mescla de fatores que correspondem à preocupação atual do grupo ou indivíduo (HALBWACHS, 2003). O ambiente em que o indivíduo vive, no caso, a sociedade, é a condição necessária para mantê-la.

A memória se sustenta nos pontos de referência social, nos vínculos sociais; existe na permanência do grupo; e se fortalece nas relações mantidas por estes. Como necessita desse vínculo para se manter, a dispersão desse grupo tende a enfraquecer a memória (HALBWACHS, 2003).

Para a memória ser evocada ela deve ser construída socialmente, e esse processo de construção não é finito: ele sofre reconstrução constantemente; necessita também de atualização, que é fundamentada na relação interpessoal (HALBWACHS, 2003). O processo de evocação da memória pode ser auxiliado pela materialidade, é o momento em que um item pode representar algo além do material.

Nora (1993) usa a teoria de Halbwachs (2003) para interpretar os lugares que podem ancorar a memória, o autor afirma que necessitamos de lugares; um fio condutor; um modo de relegar a um item a capacidade de manter uma representação coletiva.

Assim, para Nora (1993), a memória necessita de lugares porque não existe mais. Os lugares unificam a identidade da sociedade, desse modo, representando o que eles querem e necessitam manter para a posteridade. Convém pontuar que: a materialidade não é capaz de representar sozinha a memória; são os efeitos que ela causa no indivíduo que fornecem os subsídios necessários para que, em contexto social, ela seja evocada.

As formas de armazenamento podem situar a memória numa condição dual: despertar a lembrança, quando os materiais apresentam vínculo com o vivido; e promover o esquecimento, nesse caso, quando a evocação não é incentivada. Cabe ao sujeito dar os significados e estabelecer suas representações. 


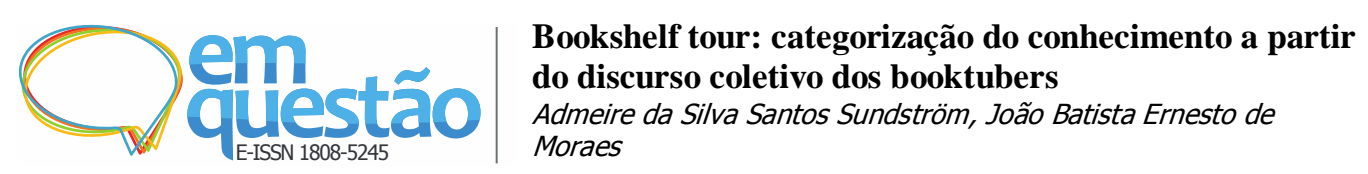

As recordações de um indivíduo podem estar ligadas a determinados objetos. E, conforme a leitura de Benjamin (1987), essas recordações também podem ser evocadas por meio do contato com livros.

Como pontuado anteriormente, a web 2.0 apresenta um novo paradigma de organização e recuperação da informação, dessa forma, também permitiu o surgimento de comunidades distantes geograficamente, mas próximas no ciberespaço. E, após as explanações dos conceitos pertinentes para analisar os dados, cabe pontuar a respeito da Comunidade Booktube, composta por pessoas amantes de livros e literatura, que são também colecionadores de livros e divulgam suas coleções na internet, bem como, os tratamentos correspondentes às formas particulares e à organização e recuperação do conhecimento.

\subsection{Booktubers}

O YouTube foi criado em 2005, por Chad Harley, Stev Chen e Jawed Karim, e comprado pela Google em 2006 (JEFFMAN, 2015). É uma ferramenta de compartilhamento de vídeos na qual os usuários podem ser os produtores e consumidores. Os vídeos são elaborados de acordo com o perfil do produtor/consumidor. A plataforma tem ganhado inúmeros usuários; se tornou uma poderosa ferramenta de marketing; e está modificando as formas contemporâneas de entretenimento . Tudo isso, acompanhado de um novo padrão de necessidade e com uma linguagem própria.

Diante da diversidade de conteúdo disposto na plataforma é que esta comunicação se volta para a comunidade booktube. Após levantamento bibliográfico, percebe-se a pouca incidência de estudos sobre o assunto, e, por se tratar de neologismo, o significado da palavra ainda não está disposto em dicionários de língua inglesa e nem portuguesa, assim, os autores buscam as definições dos conceitos, necessárias para o desenvolvimento de estudos sobre a observação do comportamento dos integrantes dessa comunidade.

Desse modo, Booktube consiste em: “[...] um tipo de canal de vídeo dentro da rede social online YouTube, com a temática voltada, principalmente, para o universo literário." (PAIVA; SOUZA, 2017, p. 979). A palavra canal é 
utilizada para se referenciar a página na qual o usuário posta os seus vídeos, e os usuários podem se inscrever gratuitamente. Booktube é o termo utilizado para abranger essa categoria de vídeo dentro do YouTube, cujo núcleo comum é a abordagem voltada para a literatura.

Jeffman (2015) conceitua booktube como um canal, propriamente dito, cuja finalidade é falar sobre livros no YouTube, onde são, assim, compartilhadas resenhas, opiniões pessoais, sugestões de compra de livros, e outros. Desse modo, Booktube pode ser entendido como uma comunidade composta por pessoas, unidas no ciberespaço, que gostam de ler, comentar e ouvir a respeito de livros

Etimologicamente, o neologismo é junção de duas palavras americanas book (livro) mais tube (gíria para televisão). A tradução ao pé da letra seria livro na televisão, ou livro na tela. A origem do termo se deu em 2011, nos Estados Unidos, mas os vídeos dessa categoria existiam bem antes da terminologia surgir, o que dificulta a identificação do primeiro vídeo do gênero por parte dos pesquisadores (PAIVA; SOUZA, 2017).

Assim, booktuber é a pessoa, também identificada como influenciador digital, responsável pelo canal no qual posta os vídeos. São geralmente jovens que, norteados pelos interesses pessoais, ou moda lançada na plataforma, compartilham suas experiências literárias. Booktuber é um adjetivo "[...] que articula a palavra book (livro, em inglês) com tuber (referência ao produtor de conteúdo YouTube).” (TEIXEIRA; COSTA, 2016, p. 22).

Balverdu (2014) identifica, em sua pesquisa, o perfil dos booktubers brasileiros e de seus seguidores. A autora coleta dados por meio de questionário e, no que tange às perguntas direcionadas aos booktubers, pode-se dizer que estão divididas em dois grupos: o primeiro bloco é voltado para questão de ordem pessoal; o outro, a respeito da percepção do booktuber em relação ao canal.

Ao observar as respostas tabuladas pela autora, conclui-se que os booktubers produzem esse tipo de vídeo porque sentem a necessidade de compartilhar suas leituras com alguém; de interagir o seu gosto pessoal sobre 


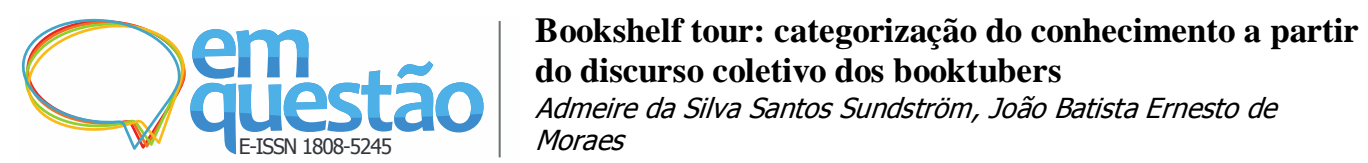

literatura com outros que desfruam a mesma opinião; e incentivar a leitura (BALVERDU, 2014).

Outra conclusão relevante é que boa parte dos booktubers afirmam considerar os textos escritos, que falam sobre livros, "frios e sem assunto", ou, até mesmo, que a resenha é "gigante", que conota algo enfadonho. Eles afirmam que, para falar de livros, o vídeo tem um retorno melhor do que a escrita, pois permite a sensação de mais proximidade com o outro e, também, atingem um público que não gosta de ler. Afirmam, também, que a informalidade do vídeo proporciona uma sensação de intimidade entre quem cria e quem assiste, pois, a linguagem utilizada facilita a interação (BALVERDU, 2014).

A análise da autora, em relação aos inscritos, é que eles, de fato, norteiam suas compras pelo que os booktubers comentam e sugerem. Também ampliam suas leituras e gostam de compartilhar o que leem com os booktubers. Muitos inscritos começaram a ler após assistirem aos vídeos dos canais, pois se sentiram "motivados" para tal. Sobre as resenhas dos livros, as respostas são bem divididas, assim, existem usuários que gostam de ambos: resenha e vídeo; outros que não gostam de ler sobre livros; e os que preferem apenas os vídeos.

Nesta comunicação, como o intuito é abordar o colecionismo, será analisado a TAG Bookshelf Tour que, quando traduzido ao pé da letra significa: passeio pela estante de livros.

Mas, para a comunidade booktube, o conceito de Bookshelf Tour é mais abrangente e "[...] consiste na exibição da estante de livros para os seguidores, comentando-se brevemente os livros preferidos, em que período da vida a obra foi lida e como se deu a aquisição do livro (compra, troca, presente, furto da biblioteca da escola, etc.).” (TEIXEIRA E COSTA, 2016, p. 24).

No passeio pela estante, alguns booktubers explicitam suas motivações para aquisição dos livros e contextualizam esse processo com momentos de suas vidas. Alguns aproveitam o momento para explicar como a biblioteca se organiza; como a organização é importante para sua rotina de leitura; e, ainda, apresentam a organização como uma opção para seus seguidores. 


\section{METODOLOGIA E ANÁLISE DOS DADOS}

O método escolhido para analisar os dados foi o Discurso do Sujeito Coletivo (DSC), trabalhado por Fernando Lefevre, Ana Lefevre (2014) e também por estes autores com Marques (2009). Por meio dessa metodologia, é possível identificar as Representações Sociais ${ }^{1}$ presentes nas falas de determinado grupo. Desse modo, “[...] as opiniões ou expressões individuais que apresentam sentidos semelhantes são agrupadas em categorias semânticas gerais [...]" (LEFEVRE, F.; LEFEVRE, A., 2014, p. 503).

Os autores pontuam que o Discurso do Sujeito Coletivo (DSC) é um modo de processar depoimentos. Tal processamento ocorre sob o respaldo de "um pano de fundo teórico", que irá subsidiar a interpretação dos resultados (LEFEVRE, F.; LEFEVRE, A.; MARQUES, 2009).

[...] o discurso do sujeito coletivo, como técnica de processamento de depoimentos, consiste em reunir, em pesquisas sociais empíricas, sob a forma de discursos únicos redigidos na primeira pessoa do singular, conteúdos de depoimentos com sentidos semelhantes. (LEFEVRE, F.; LEFEVRE, A.; MARQUES, 2009).

Para os autores, o DSC consiste em confrontar dois discursos: o primeiro é o discurso empírico dos sujeitos analisados, no qual se delineia as representações sociais que serão analisadas; o outro é o discurso do pesquisador que, vestido do aporte teórico, irá interpretar e entender a fala dos grupos (LEFEVRE, F.; LEFEVRE, A.; MARQUES, 2009).

Desse modo, por meio do DSC, é possível evidenciar determinado pensamento coletivo, a auto-organização desse pensamento e a viabilização das representações sociais presentes no discurso do sujeito (LEFEVRE, F.; LEFEVRE, A.; MARQUES, 2009). E, nessa concepção, os discursos dos booktubers foram transcritos, com vistas a identificar as categorias em comum presentes nesse grupo no momento de elaborar critérios de organização.

O primeiro passo foi selecionar os canais, devido à quantidade de canais, o critério para escolha foi o número de inscritos. A coleta de dados foi feita pela observação de vídeos postados na plataforma YouTube durante o mês de março 
e maio de 2018. E alguns trechos foram selecionados para transcrição. Os trechos escolhidos levaram em consideração as leituras de Benjamin (1987) a respeito das lembranças ao desempacotar a biblioteca, bem como os aspectos relacionados à organização e os aspectos descritivos e temáticos.

A análise corresponde a cinco canais, que são: The Tiny Little Things, Pamela Gonçalves, Nuvem literária, Ler antes de morrer e Chiclete violeta.

Quadro 2 - Informações dos Canais Booktubes Brasileiros

\begin{tabular}{|c|c|c|c|}
\hline \multicolumn{5}{|c|}{ Canais analisados } \\
\hline Nome do canal & Vídeos assistidos & Inscritos no canal & Visualizações \\
\hline The Tiny Little Things & 10 & $280 \mathrm{mil}$ & 28.313 .490 \\
\hline Pamela Gonçalves & 5 & $231 \mathrm{mil}$ & 11.702 .562 \\
\hline Nuvem literária & 5 & $125 \mathrm{mil}$ & 5.703 .586 \\
\hline Ler Antes de Morrer & 7 & $165 \mathrm{mil}$ & 7.039 .353 \\
\hline Chiclete Violeta & 1 (45 minutos) & $115 \mathrm{mil}$ & 4.990 .286 \\
\hline
\end{tabular}

Fonte: Dados da pesquisa.

The Tiny Little Things é o mais antigo dos canais booktube analisados, a booktuber responsável é Tattiana Feltrin e o canal está no ar desde 23 de setembro de 2007. A booktuber é formada em Letras, Tradução e Interpretação, e afirma, na descrição do canal, que o objetivo dos seus vídeos é compartilhar o amor pelos livros e incentivar a leitura.

Pamela Gonçalves afirma, na descrição, que seu canal é sobre livros, além de também ter por objetivo dar dicas sobre escrita. A booktuber é também escritora, e já publicou livros, que são: Boa Noite e Uma História de Verão; $O$ Amor Nos Tempos de \#Likes e Turma da Mônica Jovem: Uma Viagem Inesperada (YouTube, online).

O Canal Nuvem literária, da booktuber Juliana Cirqueira, está inscrito no YouTube desde 23 de agosto de 2013 (YouTube, online). Na descrição do canal, ela afirma que os vídeos falam sobre livros e literatura e outros assuntos que ela acredita serem relevantes para a discussão.

Ler Antes de Morrer é de Isabella Lubrano, formada em Jornalismo pela USP, a booktuber está com o canal desde 4 de maio de 2014. Na descrição do canal, a booktuber afirma que a meta é ler e fazer resenha de 1001 livros. 
O canal Chiclete Violeta é da Booktuber Victória, está no ar desde $1^{\circ}$ de outubro de 2011. Victória afirma que o canal é destinado a tratar de assuntos literários. Convém considerar que, como os canais estão em atividade, os dados referentes à visualização e às informações transcritas podem mudar, pois a TAG Bookshelf Tour é feita anualmente ou conforme a solicitação dos inscritos nos canais. Assim, seguem abaixo as falas coletadas para análise; e que foram utilizadas para destacar os termos presentes nas categorias de organização.

Quadro 3 - Estruturação de categorias por meio do discurso dos booktubers

\begin{tabular}{|c|c|c|}
\hline \multicolumn{3}{|c|}{ Frases analisadas } \\
\hline Nome do Canal & Frases transcritas & Termos extraídos \\
\hline Ler Antes de Morrer & $\begin{array}{l}\text { Muitos livros aqui do meu tempo de faculdade, } \\
\text { de faculdades, né? Porque eu fiz duas } \\
\text { faculdades: uma Direito e outra de Jornalismo. } \\
\text { Os livros de direito quase todos eu passei } \\
\text { adiante, eu dei para o meu irmão, que depois } \\
\text { também entrou na faculdade de Direito, ou eu } \\
\text { joguei fora mesmo, eles [os livros] não me } \\
\text { davam boas lembranças. Mas esse aqui o "O } \\
\text { oráculo de delfos" eu guardei, porque ele foi } \\
\text { um livro que tive que ler numa disciplina } \\
\text { chamada "Filosofia do direito", e é um livro } \\
\text { absurdamente difícil, eu tive, nossa! Uma } \\
\text { trabalheira para conseguir ler e fazer os } \\
\text { trabalhos, foi tão difícil que eu guardei como } \\
\text { recordação [...] }\end{array}$ & $\begin{array}{l}\text { Faculdade, } \\
\text { que trazem } \\
\text { recordações, Livros } \\
\text { que representam } \\
\text { traumas; Leitura } \\
\text { compulsória. }\end{array}$ \\
\hline Ler Antes de Morrer & $\begin{array}{l}\text { Aqui eu tenho alguns livros da época do } \\
\text { colégio }\end{array}$ & Colégio $=$ Escola \\
\hline Ler Antes de Morrer & $\begin{array}{l}\text { [...] na verdade eles não tem muita ordem, mas } \\
\text { posso dizer que esse aqui são literatura } \\
\text { brasileira. }\end{array}$ & Literatura brasileira \\
\hline Ler Antes de Morrer & $\begin{array}{l}\text { Eu guardei [o livro] para guardar na memória o } \\
\text { sofrimento que essa matéria me causava. }\end{array}$ & $\begin{array}{l}\text { Livros que } \\
\text { representam } \\
\text { traumas }\end{array}$ \\
\hline Ler Antes de Morrer & $\begin{array}{l}\text { Este livro eu preciso ler novamente para perder } \\
\text { o trauma [ao manusear Iracema, José de } \\
\text { Alencar]. }\end{array}$ & Leitura compulsória \\
\hline Ler Antes de Morrer & $\begin{array}{l}\text { Mas tive motivo para eu querer guardar este. } \\
\text { Sabe aquele livro que você lê na infância, que } \\
\text { você leu como um livro de adulto? [...] eu o } \\
\text { guardei por razões sentimentais. [Ao manusear } \\
\text { Romeu e Julieta, Shakespeare]. }\end{array}$ & $\begin{array}{l}\text { Leitura espontânea; } \\
\text { Livros que trazem } \\
\text { recordação, âmbito } \\
\text { escolar. }\end{array}$ \\
\hline Nuvem literária & $\begin{array}{l}\text { Finalmente organizei [os livros] do jeitinho que } \\
\text { eu sempre quis. Agora sim, finalmente, eu } \\
\text { tenho uma senhora estante pra conseguir fazer } \\
\text { uma Bookshelf tour atualizada pra vocês. } \\
\text { Inclusive, eu tive até que fazer uma limpeza na } \\
\text { estante mesmo, tirar alguns livros que eu não } \\
\text { utilizava mais, que não queria tanto ter na } \\
\text { minha estante, separei todos esses livros pra } \\
\text { doação, já doei, enfim, agora na estante só }\end{array}$ & $\begin{array}{l}\text { Livros para doação; } \\
\text { Gênero literário; }\end{array}$ \\
\hline
\end{tabular}




\begin{tabular}{|c|c|c|}
\hline & $\begin{array}{l}\text { tenho os livros que eu amo, ou pretendo ler } \\
\text { ainda, ou que eu realmente gosto, ou que eu } \\
\text { quero ter na minha estante. Eu separei mais ou } \\
\text { menos por gênero, enquanto deu, né? Eu } \\
\text { consegui fazer por gênero, porque depois } \\
\text { acabou que acabavam os livros e eu tinha que } \\
\text { colocar outros livros e sobrava em lugares } \\
\text { diferentes, mas ficou quase tudo por gênero } \\
\text { certinho. }\end{array}$ & \\
\hline Nuvem literária & $\begin{array}{l}\text { No lado de cá, na verdade, a gente colocou os } \\
\text { boxes, séries, trilogias, coisas assim, apesar de } \\
\text { ter algumas séries e trilogias lá em baixo } \\
\text { também e eu ter separado pra colocar aqui em } \\
\text { cima. }\end{array}$ & $\begin{array}{l}\text { Box, série } \quad \mathrm{e} \\
\text { trilogia. }\end{array}$ \\
\hline Pâmela Gonçalves & $\begin{array}{l}\text { Eu resolvi organizar de forma diferente. Na } \\
\text { verdade, eu organizei em várias ordens, assim: } \\
\text { eu primeiro dividi os livros em contemporâneo, } \\
\text { histórico e policial tudo de um lado; e do outro, } \\
\text { eu organizei: distopia, fantasia, sobrenatural e } \\
\text { paranormal, tudo do outro lado. Primeiro fiz } \\
\text { essa grande divisão. Depois, em cada uma } \\
\text { dessas categorias, eu dividi os livros que são } \\
\text { maiores e os livros que são menores, porque eu } \\
\text { queria muito organizar por tamanho, para ficar } \\
\text { bonitinho. Depois que eu organizei assim, eu } \\
\text { separei as series dos livros únicos, e também eu } \\
\text { contei como se fosse série os livros do mesmo } \\
\text { autor, sabe? }\end{array}$ & $\begin{array}{l}\begin{array}{l}\text { Dimensão } \\
\text { autorsica, } \\
\text { literário. }\end{array} \\
\text { Gênero }\end{array}$ \\
\hline Chiclete violeta & $\begin{array}{l}\text { Este livro aqui ele é muito especial para mim, } \\
\text { porque na minha formatura do quarto ano, eles } \\
\text { meio que tinham um escritor que fazia a } \\
\text { história personalizada para cada pessoa, então, } \\
\text { a personagem principal desse livro chama } \\
\text { Victória, e eu fiquei muito feliz quando recebi, } \\
\text { é muito importante pra mim. }\end{array}$ & $\begin{array}{l}\text { Livros que trazem } \\
\text { recordações. }\end{array}$ \\
\hline Chiclete violeta & $\begin{array}{l}\text { O mistério das cinco estrelas, [autor Marcos } \\
\text { Rey] eu amo esse livro, marcou minha infância. }\end{array}$ & $\begin{array}{l}\text { Livros que trazem } \\
\text { recordações (âmbito } \\
\text { familiar e escolar) }\end{array}$ \\
\hline $\begin{array}{l}\text { The Tiny Little } \\
\text { Things }\end{array}$ & $\begin{array}{l}\text { Oi, meu nome é Tatiana e eu coleciono livros; e } \\
\text { eles ficam espalhados pela casa, eles não têm } \\
\text { um lugarzinho próprio, eu não tenho um } \\
\text { cômodo onde eu coloco os livros. [...] Eles } \\
\text { ficam espalhados pela casa. }\end{array}$ & Diversidade \\
\hline
\end{tabular}

Fonte: Adaptado de YouTube (2018).

Nesta pesquisa, não se utilizou vocabulário controlado para a extração dos termos encontrados nos discursos, pois o objetivo é utilizar a linguagem natural veiculada pelos próprios booktubers e preservar essa categorização com característica popular. Assim, colégio e escola são tratados como sinônimos, pois os livros, adquiridos nessas diferentes fases da vida, estão dispostos no 
mesmo lugar nas prateleiras. Desse modo, optou-se por padronização dos termos.

Pamela Gonçalves divide suas prateleiras por gênero. Dentro do gênero, ela subdivide por livros pertencentes a sagas e trilogias. Em outra prateleira separada, estão dispostos os livros sem saga, ou os que estão com a saga incompleta. Outros critérios relacionados à descrição também são empregados no momento de categorização, pois há prateleiras em que ela classifica os livros por cor, tamanho e apego sentimental.

Ler antes de morrer, de Isabella Lubrano: no início do vídeo, a booktuber já apresenta fatos que a classificam como colecionadora, pois afirma que os livros são resultado de 15 anos de coleção. "São livros que eu ganho, livros que eu compro, livros que encontro em sebo." (LER ANTES DE MORRER, 2015, doc. não paginado). A categoria principal de Isabella é a dimensão física. Dentro dessa primeira categoria, ela os subdivide pelos momentos da vida e, dentro dessa subcategoria, ela tenta colocar os livros com assuntos similares mais próximos um dos outros.

A primeira prateleira é iniciada com os livros que ela leu durante a faculdade, e o critério para mantê-los, mesmo os da faculdade que ela abandonou, é o livro ter marcado de alguma forma (LER ANTES DE MORRER, 2015). Assim, por meio da fala da booktuber referente à sua primeira prateleira, foi possível identificar as subcategorias: livros relevantes para atuação profissional e livros que trazem traumas.

Isabella também tem uma prateleira dedicada aos livros adquiridos durante o período escolar, e, ao retirar "Iracema" e "Romeu e Julieta" da prateleira, passagens destacas no quadro acima, torna possível identificar as subcategorias: leitura compulsória e leitura espontânea.

Desse modo, o laço entre a coleção bibliográfica e a memória, visualizados em Benjamin (1987, pode ser destacado nas passagens em que Isabella compartilha as lembranças que os livros despertam, como, por exemplo, no momento que ela pega o livro que herdou da avó e fala que o primeiro a avó havia perdido e, após muita procura, pois era uma edição rara, encontrou outro exemplar da mesma edição em um sebo e deu de presente a avó. Após o 
falecimento da avó, o livro passou a compor sua coleção e traz recordações a Isabella. Dessa forma, identificamos a subcategoria Livros que trazem recordações, âmbito familiar.

Chiclete Violeta: a booktuber organiza os livros por cores e, para isso, Victória leva em consideração a lombada do livro, dessa forma ela separa os livros pelos nichos e até mesmo os enfeites das prateleiras são da cor das lombadas dos livros. As únicas exceções correspondem às sagas, que ela classifica por ordem de preferência; e os livros com mais de uma cor na lombada.

Tatiana Feltrin, do canal The Tiny Little Things, afirma que espalha os livros em pilhas pela casa. Mas, no decorrer dos vídeos foi possível perceber que os únicos livros organizados, ou o mais próximo disso, são os livros relevantes para atuação profissional, que são relacionados à gramática de língua inglesa, dicionários e outros. Mas, em nenhum momento, a colecionadora se perde no meio dos livros e cabe trazer a fala de Benjamin (1987, p. 128 “[...] a existência o colecionador é uma tensão dialética entre os polos da ordem e da desordem."

Figura 1 - Categorias identificadas no discurso dos booktubers colecionadores

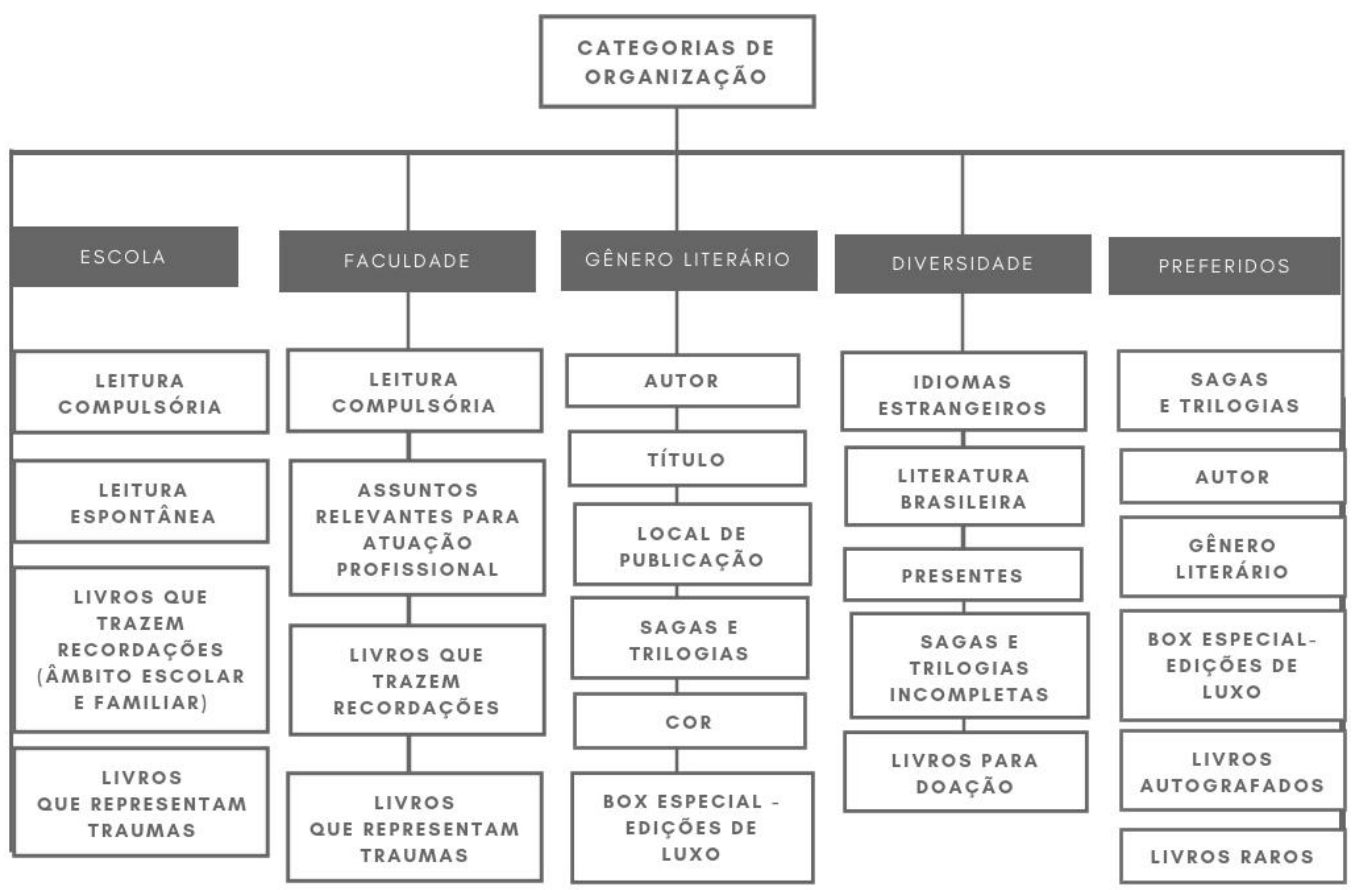

Fonte: Dados da pesquisa. 


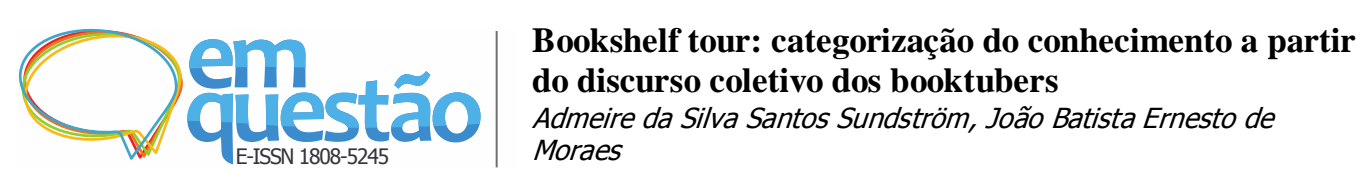

A Figura 1 apresenta as categorias identificadas no discurso dos colecionadores. Quando levados a uma concepção folksonômica, evidenciam-se termos, frutos da linguagem natural, que representam e descrevem objetos de um ponto de vista exclusivo do usuário.

Convém salientar que, a folksonomia subentende o uso de tagueamento, isto é, marcações elaboradas na internet. Mas o olhar que se lança nesta pesquisa é que, pelo fato da folksonomia ser um processo ou produto de categorização do usuário, pensa-se na viabilidade desse olhar ser aplicado para identificação desse processo no colecionismo, que também é caracterizado por classificações domésticas.

Ressalta-se que a comunidade analisada divulga seus modos de organização em ambiente aberto e com o uso de linguagem natural, sendo assim, a presença da folksonomia está na abordagem dada pelos colecionadores no momento de categorizar os objetos compartilhado na plataforma YouTube. Desse modo, a organização no contexto do colecionismo bibliográfico apresenta uma abordagem folksonômica, seja enquanto processo, ou enquanto produto.

As colaborações nas classificações aparecem em forma de comentários dos inscritos ou, até mesmo, na visualização de outros vídeos que também foram disponibilizados na plataforma, pois alguns dos booktubers analisados afirmaram que mudaram o modo de organizar de um ano para o outro.

Quando as informações foram analisadas com o olhar voltado ao conteúdo descritivo e conteúdo temático, destaca-se:

a) conteúdo descrito - conclui-se que existem dois níveis de categorias utilizadas, as primárias e as secundárias,

- como primárias destacam-se: gênero literário, série (edições seriadas), cor e tamanho,

- como categoria secundária estão: autor por ordem alfabética, livro por ordem alfabética e prioridade de leitura;

b) conteúdo temático - a organização do acervo gira em torno da vida do colecionador, desse modo, o assunto do livro é uma subcategoria. Assim, parte da categoria principal, que são os momentos vividos pelo colecionador. As análises das falas viabilizaram a conclusão de que os 
assuntos dos livros estão atrelados às razões de guarda. E tais razões são justificadas com o auxílio de momentos rememorados.

Desse modo, os momentos rememorados são primordiais para a construção de termos que identificam os livros nas prateleiras. Assim, tais termos constroem categorias que se relacionam com memória. Os livros em si funcionam como um lugar de memória e estão ali com a função de despertar o passado (NORA, 1993).

Nos casos analisados, os booktubers, ao percorrerem as prateleiras, constroem narrativas em torno na representatividade dos livros para a vida, compartilham a terminologia utilizada para identificar os livros, os critérios para guarda, dentre outros elementos. Para eles, a desorganização é identificada quando os livros, adquiridos no mesmo período da vida, estão em prateleiras diferentes.

Desse modo, acredita-se que, partindo da estruturação dessa organização e do conhecimento profundo dessa comunidade, se torna possível evidenciar os conceitos, que merecem ser ressignificado, na perspectiva da comunidade booktube.

\section{CONSIDERAÇÕES FINAIS}

$\mathrm{Na}$ construção dos argumentos finais deste artigo, cabe trazer o questionamento central e os tangenciais que nortearam a elaboração deste. Como ponto central, buscou-se responder ao questionamento se é possível aplicar a concepção de folksonomia para identificar as categorias de organização do conhecimento da comunidade booktube por meio da identificação dos termos utilizados por essa comunidade? A resposta é sim, é possível. Com auxílio de uma metodologia que identifica os termos recorrentes nas falas ou por meio da identificação dos termos utilizados para a definição do material, foi possível o estabelecimento das categorias utilizadas pela comunidade.

No que se refere à presença da memória, afirma-se que ela está intimamente ligada aos elementos de descrição temática, pois o conteúdo do livro, quando comentado pelos booktubers, está atrelado a vivências dos 
colecionadores. Outro questionamento é a respeito das contribuições dos estudos em torno de instâncias populares de organização e suas contribuições para pesquisa em torno da Organização e Representação do Conhecimento (ORC). As instâncias particulares demonstram a exaustividade da linguagem natural na descrição de um item, apesar da recuperação se tornar mais devagar devido à quantidade de elementos recuperados, esse olhar apresenta um modo estruturado de organização.

Destaca-se, também, que a linguagem natural pode ser importante para o mapeamento conceitual do usuário e para a categorização da estrutura de organização nesse ambiente. Assim, a compreensão em torno da folksonomia vai além de um produto e processo em rede de compartilhamento digital. Mas, também, se torna mecanismo para olhar coleções que utilizam da organização social para categorizar seus sistemas de organização do conhecimento.

No decorrer da análise dos termos extraídos no discurso dos booktubers, foi possível compreender a complexidade da pesquisa e seus possíveis desdobramentos, em que mais canais necessitam ser analisados para maior compreensão das nuances e particularidades que permeiam essa comunidade discursiva. Salienta-se a necessidade de se identificar o que Kobashi e Francelin (2011) nomeiam de Sistema nocional, que parte dos modos que essa comunidade organiza o conhecimento para a definição dos conceitos.

\section{REFERENCIAS}

BALVERDU, Andressa Machado. Comunidade booktube como alternativa de incentivo à leitura. 2014. Trabalho de Conclusão de Curso (Bacharelado em Biblioteconomia) - Universidade Federal de Rio Grande do Sul, Porto Alegre, 2014.

BARROS, Léa Maria de Souza. A folksonomia como prática de classificação colaborativa para a recuperação da informação. 2011. Dissertação (Mestrado em Ciência da Informação) - Instituto brasileiro de Informação em Ciência e Tecnologia, Universidade Federal do Rio de Janeiro, Rio de Janeiro, 2011.

BARITÉ, M. Organización del conocimiento: un nuevo marco teóricoconceptual en Bibliotecología y Documentación. In: CARRARA, K. (Org.). Educação, universidade e pesquisa. Marília: Unesp Marília 2001. p. 35-60. 


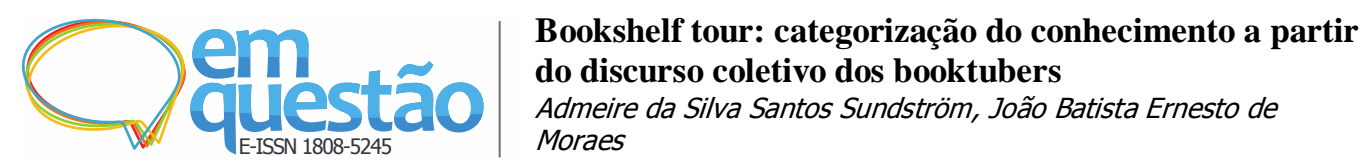

BARTLETT, Allison Hoover. O homem que amava muito os livros: a história real de um ladrão bibliófilo, um detetive e os bastidores do universo dos colecionadores literários. São Paulo: Seoman, 2013.

BENJAMIN, Walter. Desempacotando minha biblioteca: um discurso sobre o colecionador. In: BENJAMIN, Walter. Rua de mão única: obras escolhidas. São Paulo: Brasileiense, 1987. v. 2.

BLISS, Henry. Organization of knowledge in libraries and the subjectapproach to books. New York: Wilson, 1933.

CATARINO, Maria Elizabete; BAPTISTA, Ana Alice. Folksonomia: um novo conceito para a organização dos recursos digitais na web. DataGramaZero, Rio de Janeiro v. 8, n. 3, p. A04-0, 2007.

CHICLETE VIOLETA. Produtora: Victória. Online disponibilizado no YouTube. Color.

FORMANEK, Ruth. Why they collect: collectors reveal their motivations. In: PEARCE, Susan (Org.). Interpreting objects and collections. New York: Routledge, 2005. cap. 38, p. 327-335.

GOMES, Hagar Espanha. Tendências da pesquisa em organização do conhecimento. Pesquisa brasileira em Ciência da Informação, Brasília, v.2, n. 1, p. 60-88, jan./dez. 2009.

HALBWACHS, Maurice. A memória coletiva. São Paulo: Centauro, 2003

JEFFMAN, Tauna Mariana Weinberg. Literatura compartilhada: uma análise da cultura participativa, consumo e conexões nos booktubers. Revista Brasileira de História da Mídia, São Paulo, v. 4, n. 2, p. 99-108, jul. 2015.

KOBASHI, Nair Yumiko; FRANCELIN, Marivalde Moacir. Conceitos, categorias e organização do conhecimento. Informação \& Informação, Londrina, v. 16, n. 2, p. 1-24, jan./jun. 2011.

LEFEVRE, Fernando; LEFEVRE, Ana Maria Cavalcanti. Discurso do sujeito coletivo: representações sociais e intervenções comunicativas. Texto Contexto, Florianópolis, v. 23, n. 2, p. 502-507, abr./jun. 2014.

LEFEVRE, Fernando; LEFEVRE, Ana Maria Cavalcanti; MARQUES, Maria Cristina da Costa. Discurso do sujeito coletivo, complexidade e autoorganização. Ciência \& Saúde Coletiva, Rio de Janeiro, v. 14, n. 4, p. 1193 1204, 2009.

LER ANTES DE MORRER. Produtora: Isabella Lubrano. 2015. Online disponibilizado no YouTube. Color. 
MOURA, Maria Aparecida. Informação, ferramentas ontológicas e redes sociais ad hoc: a interoperabilidade na construção de tesauros e ontologias. Informação \& Sociedade, João Pessoa, v. 19, n. 1, p. 59-73, 2009.

MURGUIA, Eduardo Ismael. O colecionismo bibliográfico: uma reflexão sobre o livro para além da informação. Encontros Bibli, Florianópolis, n. esp, p. 87 $104,2009$.

NORA, Pierre. Entre memória e história: o problema dos lugares. Revista do programa de Pós-graduados e do departamento de história da PUC-USP, São Paulo, v. 10, p. 7-28, 1993.

NUVEM LITERÁRIA. Produtora: Ju Cirqueira. 2016. Online disponibilizado no YouTube. Color.

PAIVA, Sthéfani; SOUZA, Adriana Maria de. Booktube como instrumento de disseminação da informação para a geração digital. Revista Brasileira de Biblioteconomia e Documentação, São Paulo, v. 13, n. esp., p. 978-1003, 2017.

PAMELA GONÇALVES. Produtora: Pamela Gonçalves. 2016. Online disponibilizado no YouTube. Color.

SANTOS, Hercules Pimenta. Etiquetagem e folksonomia: o usuário e sua motivaçÃo para organizar e compartilhar informação na web 2.0. Perspectivas em Ciência da Informação, Belo Horizonte, v. 18, n. 2, 2013.

SANTOS, Admeire da Silva. A influência do colecionismo na representação da memória social: análise da coleção Amidicis Tocantins. 2015. Dissertação (Mestrado em Ciência da Informação) - Faculdade de Filosofia e Ciências, Universidade Estadual Paulista Júlio de Mesquita Filho, Marília, 2015.

TEIXEIRA, Cládia Souza; COSTA, Andressa Abrãao. Movimento booktubers: práticas emergentes de mediação de leitura. Texto Livro, Belo Horizonte, v. 9, n. 2, p. 13-31, jul./dez. 2016.

THE TINY LITTLE THINGS. Produtora: Tatiana Feltrin. 2013. Online disponibilizado no YouTube. Color.

WAL, Thomas Vander. Folksonomy coinage and definition. 2007. Disponível em: http://vanderwal.net/folksonomy.html. Acesso em: 12 dez. 2018. 


\title{
Bookshelf tour: categorização do conhecimento a partir do discurso coletivo dos booktubers \\ Admeire da Silva Santos Sundström, João Batista Ernesto de Moraes
}

\section{Bookshelf tour: the categorization of knowledge from the colletive discourse of booktubers}

\begin{abstract}
There are many ways of organizing knowledge, and this makes possible and necessary the study of popular instances of knowledge organization. In this research, the object of study is the booktube community. It is composed of people who share their literary experiences through videos posted on the YouTube platform. Video reviews allowed classifying certain booktubers as book collectors. It is understood that bibliographic collecting occurs in a particular instance, it is motivated by subjective reasons and the organization of these collections follows the particular order of each collector, thus, it is questioned: Is it possible to apply the concept of folksonomy to identify the categories of knowledge organization of the booktube community? The method consists of two stages: the first consists in the construction of the theoretical contribution, which sought the conceptual definition of the relevant subjects for analysis and interpretation of the data. From this, comes the second stage, which consists in the use of the Discourse of the Collective Subject to identify the terms used by the community in question. As a result, we noticed the presence of categories of organizations, the possibility of using the Collective Subject Discourse to categorize natural language and the collective memory implicit in this system. Finally, it is possible to use the concept of Folksonomy to identify modes of organization in collecting, the pros and cons of natural language in a conceptual framework and the possibility of interpreting Folksonomy in other environments beyond the current approach of process or product of web 2.0.
\end{abstract}

Keywords: Booktubers. Bibliographic collection. Collective memory. Folksonomy. Knowledge organization.

Recebido: 16/05/2018 Aceito: 01/08/2018

\footnotetext{
${ }^{1}$ De acordo com os autores "As representações sociais são esquemas sociocognitivos de que as pessoas lançam mão para emitirem, no cotidiano de suas vidas, juízos ou opiniões, que são condições necessárias para viver e se comunicar em sociedades complexas." (LEFEVRE, F.; LEFEVRE, A., 2009).
} 